\title{
Perfil de Compostos Fenólicos da Nannochloropsis oculata com Promissora Atividade Antifúngica
}

\author{
Priscila Tessmer Scaglioni (I), Paulo Cesar Oliveira Vergne de \\ Abreu (II), Eliana Badiale Furlong (I) \\ (I) FURG - Universidade Federal do Rio Grande (Avenida Itália km 8 - Programa de Pós- \\ Graduação em Eng e Ciência de Alimentos), (II) FURG - Universidade Federal do Rio Grande \\ (Avenida Itália km 8 - Instituto de Oceanografia)
}

\section{Resumo}

A microalga Nannochloropsis oculata é amplamente distribuída nos oceanos e não são conhecidos efeitos nocivos de sua classe na natureza. Por sua facilidade de cultivo, tamanho pequeno, velocidade de crescimento e alto teor de ácidos graxos poliinsaturados, essas microalgas são bastante utilizadas na aquicultura, como alimento para rotíferos e para criar efeito verde em tanques de larvas. O objetivo deste estudo foi identificar os compostos fenólicos solúveis em metanol presentes na N. oculata, para futura aplicação destes como antifúngicos naturais em diversos produtos. Foi utilizada biomassa da microalga seca e moída até 32 mesh, os compostos fenólicos foram extraídos com metanol (1:4 m/v) em mesa orbital a temperatura ambiente por $2 \mathrm{~h}$ e $30 \mathrm{~min}$ e foi realizada uma clarificação com hidróxido de bário $0,1 \mathrm{M}$ e sulfato de zinco 5\%. Estes compostos foram quantificados por cromatografia líquida de alta eficiência com detector ultravioleta, utilizando fluxo de $0,7 \mathrm{~mL} \mathrm{~min}^{-1}$, temperatura de $35{ }^{\circ} \mathrm{C}$, coluna de fase reversa $\mathrm{C} 18(4,6 \times 250 \mathrm{~mm}, 5 \mu \mathrm{m})$ e um gradiente isocrático de solventes constituído por metanol e água acidificada (ácido acético $1 \%$ ) na relação $20: 80 \mathrm{v} / \mathrm{v}$, durante $25 \mathrm{~min}$, e detecção a $280 \mathrm{~nm}$ até 15 min e $320 \mathrm{~nm}$ até $25 \mathrm{~min}$. Padrões de ácidos fenólicos foram usados para identificação dos ácidos fenólicos nos extratos e para construção das curvas padrão. Os ácidos fenólicos identificados e determinados na $\mathrm{N}$. oculata foram: ácido gálico $\left(198 \mu \mathrm{g} \mathrm{g}^{-1}\right)$, protocatecóico $\left(7 \mu \mathrm{g} \mathrm{g}^{-1}\right)$, clorogênico $\left(26 \mu \mathrm{g} \mathrm{g}^{-1}\right)$, hidroxibenzóico $\left(10 \mu \mathrm{g} \mathrm{g}^{-1}\right)$, cafeico $\left(13 \mu \mathrm{g} \mathrm{g}^{-1}\right)$, 
siríngico $\left(6 \mu \mathrm{g} \mathrm{g}^{-1}\right)$, vanilina $\left(6 \mu \mathrm{g} \mathrm{g}^{-1}\right)$, cumárico $\left(7 \mu \mathrm{g} \mathrm{g}^{-1}\right)$ e ferúlico $(8 \mu \mathrm{g}$ $\left.\mathrm{g}^{-1}\right)$. O que totalizou um teor de $280 \mu \mathrm{g} \mathrm{g}^{-1}$, representados majoritariamente (70\%) pelo ácido gálico. Existem estudos na literatura que indicam a capacidade antioxidante de compostos semelhantes extraídos desta microalga, porém ainda não há comprovação da sua eficiência quanto a atividade antifúngica, mas a presença deste ácidos provenientes de outras fontes mostram ser promissora para inibir espécies fúngicas. Experimentos para avaliar estas propriedades estão sendo conduzidos.

Palavras-Chave: ácido gálico, fenóis, Nannochloropsis

Agência de Fomento: 